\title{
Oestrogen receptors and breast cancer
}

\author{
It is time for individualised treatment based on oestrogen receptor status
}

$\mathrm{B}$ reast cancer is marked by great clinical and biological diversity. Some women can be cured, while others die rapidly over just a few months. Systemic treatments can have gratifying and possibly curative effects for some, while for others they add only misery and financial hardship. Given this great heterogeneity, are women with breast cancer best served by therapeutic approaches emphasising homogeneity or ones that reflect the variability of the disease in individual choices of treatment? A case in point is the use of oestrogen receptor status in making decisions about endocrine therapy.

Oestrogen receptors are required for oestrogen stimulated growth and proliferation of breast cancer. They are found to some degree in $50-80 \%$ of breast tumours. Endocrine treatments are designed to antagonise the effects of oestrogen. Oophorectomy, luteinising hormone releasing hormone agonists, and aromatase inhibition all reduce the level of oestrogen, while antioestrogens such as tamoxifen competitively block binding of oestrogen to receptors and thus antagonise transcriptional activation of genes required for tumour growth.

Twenty five years ago it was first hypothesised that the response to such endocrine treatments would depend on the presence of oestrogen receptors in the tumours. And indeed, 50-60\% of receptor positive metastatic tumours do respond. ${ }^{1}$ For tumours that test negative for oestrogen and progesterone receptors, the response rate (in terms of tumour size reduction or prolonged stability) is less than $5 \% .^{2}$ However, when less stringent cut off points are selected for defining receptor negativity, response rates increase, since even tumours with very low receptor positivity (between 4 and $10 \mathrm{fmol} / \mathrm{mg}$ protein) show a $20-30 \%$ response to treatment. ${ }^{3}$

Similarly, in the context of adjuvant endocrine treatment, oestrogen receptor status predicts the benefit of tamoxifen in preventing or delaying recurrence. In a meta-analysis of trials of adjuvant treatment there seemed to be a small benefit even in tumours with low concentrations of oestrogen receptors, but this was with a relatively high cut off point of $10 \mathrm{fmol} / \mathrm{mg}^{4}$ This group would include women whose tumours had low concentrations of oestrogen receptors as well as those with receptor negative tumours, so that it is not surprising that there was some benefit. Similarly, our group recently found that if tumours contained even $1 \%$ of receptor positive cells by immunohistochemistry, there was evidence of significant benefit from adjuvant endocrine treatment. ${ }^{5}$ Individual trials using more stringent cut off points, such as a Swedish trial, ${ }^{6}$ find no benefit from adjuvant tamoxifen treatment in receptor negative tumours.

The apparent benefits of endocrine treatment in some "receptor negative" tumours have contributed to suggestions that all patients should receive tamoxifen independent of their oestrogen receptor status. But these apparent benefits depend to a considerable extent on the cut off point that was used. If cut off points are very low, then this suggestion would mean that 19 patients with receptor negative tumours would have to receive ineffective treatment for each one who benefits.

It could also be argued that tamoxifen should be given to all patients, including those with receptor negative tumours, because it has other benefits besides decreasing recurrence. These benefits might include decreasing the incidence of contralateral breast cancer, ${ }^{4}$ slowing postmenopausal bone loss, ${ }^{7}$ and improving the blood lipid profile. ${ }^{8}$ However, none of these potential benefits has much relevance to a woman with metastatic disease, and even a low level of side effects can erode or obliterate small benefits. Tamoxifen is generally well tolerated but is not completely without problems. Women receiving adjuvant tamoxifen treatment have an apparent increased risk of deep venous thromboses and pulmonary emboli of 1-2 patients/1000/year ${ }^{9}$ and a probable increased risk of endometrial cancer of about one patient/1000/year. ${ }^{10}$ Whether this is worth a decrease of two to three breast cancers per 1000 per year is debatable.

It has also been argued that determining oestrogen receptor status is too complicated for routine practice. There are, indeed, many assay methods available, but all clinically practical methods are based either on competitive binding of a labelled ligand or on the recognition of receptor protein by specific antibodies. ${ }^{11}$ The prototype ligand binding method is the dextran coated charcoal assay, in which radiolabelled oestradiol is allowed to bind to the receptor in a tumour cytosol and the amount bound is expressed in $\mathrm{fmol} / \mathrm{mg}$ total cytosol protein. Antibody recognition of oestrogen receptors is most often assessed by immunohistochemistry, in which a histological section is stained by an antibody specifically directed against unique receptor epitopes and the percentage of cells with stained nuclei is recorded. The main advantages of the newer immunohistochemical method are that only tumour cells are assessed, so that results are not diluted by non-tumour tissue, and that it can be performed inexpensively on 
routine permanent sections with no particularly specialised equipment. Furthermore, simple immunohistochemistry seems to be at least as good as the ligand binding assay in predicting a better outcome for receptor positive tumours. ${ }^{5}$

A final point is that the economics of the indiscriminate use of tamoxifen are not favourable. In the United States a five year course of adjuvant tamoxifen costs about $\$ 4000$ for the drug alone. To treat 100 patients for five years would therefore cost $\$ 400000$. The cost of immunohistochemical testing for oestrogen and progesterone receptors is between $\$ 50$ and $\$ 100$, so that testing 100 patients would cost at most $\$ 10000$. If $20 \%$ of these patients had tumours that were negative for both types of receptor and were not given tamoxifen, $\$ 80000$ would be saved, eight times the amount spent on the screening test. Though the cost of tamoxifen in Britain might be substantially less, the difference is unlikely to be enough to alter the balance of this financial equation. Thus, if screening for oestrogen and progesterone receptors could identify patients who have little or no chance of responding to tamoxifen, this would save resources and spare patients the morbidity of unnecessary treatment.

In summary, determining oestrogen and progesterone receptor status is easy and inexpensive, particularly by means of immunohistochemistry. When the cut off point is stringently set low and the assay is of high quality, patients with oestrogen and progesterone receptor negative tumours will experience little, if any, benefit from tamoxifen, especially as an adjuvant treatment. For metastatic disease, treating oestrogen receptor negative tumours with tamoxifen simply delays the institution of more appropriate treatment and increases the probability of patients experiencing tumour related side effects while waiting for a response that seldom occurs. It is time to move towards individualised management for women with breast cancer, making treatment more effective, timely, and cost efficient.

\section{Richard M Elledge Assistant professor}

\section{Kent Osborne Professor}

Division of Medical Oncology and Radiation Oncology, University of Texas Health Science Center, San Antonio, TX 78284-7884, USA

1 Ravdin P, Green S, Dorr T, McGuire W, Fabian C, Pugh R, et al. Prognostic significance of progesterone receptor levels in estrogen receptorpositive patients with metastatic breast cancer treated with tamoxifen: results of a prospective southwest oncology group study. J Clin Oncol 1992;10(8):1284-91.

2 Bezwoda WR, Esser JD, Dansey R, Kessel I, Rad MM, Lange M. The value of estrogen and progesterone receptor determinations in advanced breast cancer. Cancer 1991;68:867-72.

3 Knight WA III, Osborne CK, McGuire WL. Hormone receptors in primary and advanced breast cancer. Clin Endocrinol Metab 1980;9;361-8.

4 Early Breast Cancer Trialists' Collaborative Group. Systemic treatment of early breast cancer by hormonal, cytotoxic, or immune therapy: 133 randomised trials involving 31,000 recurrences and 24,000 deaths among 75,000 women. Lancet 1992;339:1-15.

5 Clark GM, Harvey JM, Osborne CK, Allred DC. Estrogen receptor status determined by immunohistochemistry is superior to biochemical ligandbinding assay for evaluating breast cancer patients. Proc Am Soc Clin Oncol 1997;16:129.

6 Rutqvist LE, Cedermark B, Fornander T, Glas U, Johansson H, Nordenskjöld B, et al. The relationship between hormone receptor content and the effect of adjuvant tamoxifen in operable breast cancer.J Clin Oncol 1989;7:1474-84.

7 Powles TJ, Hickish T, Kanis JA, Tidy A, Ashley S. Effect of tamoxifen on bone mineral density measured by dual-energy X-ray absorptiometry in healthy premenopausal and postmenopausal women. J Clin Oncol 1996; 14:78-84.

8 Love RR, Wiebe DA, Newcomb PA, Cameron L, Leventhal H, Jordan VC, et al. Effects of tamoxifen on cardiovascular risk factors in postmenopausal women. Ann Intern Med 1991;115:860-4.

9 Fisher B, Constantino J, Redmond C, Poisson R, Bowman D, Couture J, et al. A randomized clinical trial evaluating tamoxifen in the treatment of patients with node-negative breast cancer who have estrogen-receptorpositive tumours. N Engl J Med 1989;320:479-84.

10 Fisher B, Costantino JP, Redmond CK, Fisher ER, Wickerham DL, Cronin WM, et al. Endometrial cancer in tamoxifen-treated breast cancer patients: findings from the national surgical adjuvant breast and bowel projects (NSABP) B-14. J Natl Cancer Inst 1994;86:527-37.

11 Osborne CK, Elledge RM, Fuqua SAW. Estrogen receptors in breast cancer therapy. Sci Am Sci Med 1996;3:32-41.

\section{Reforming the New Zealand health reforms}

\section{Big bang gives way to incrementalism as competition is abandoned}

I n common with several other countries, New Zealand has embarked on a far reaching programme of market oriented reforms in recent years. These reforms involved separating purchaser and provider responsibilities and using contracts and competition in an attempt to increase efficiency and enhance services' responsiveness. The former National government used its parliamentary majority to push these changes through quickly, starting in 1993. The big bang that resulted sent out a series of shock waves, and the effects continue to be felt.

As Hornblow notes in this week's BMJ (p 1892), ${ }^{1}$ although the reforms have brought some benefits, overall they have failed to produce the improvements in performance that were anticipated. Furthermore, there have been several adverse consequences that have provoked opposition to the direction of change. Notwithstanding the argument that over a longer period the reforms might have worked as intended, ${ }^{2}$ steps have been taken to address the problems that have arisen and to put in place new policies.
The election of a coalition government last autumn, bringing together the National party and New Zealand First, has already resulted in a commitment to abandon competition in favour of collaboration. The new government's statement on health policy includes a promise to replace commercial objectives with principles of public service while seeking to make the health service businesslike. ${ }^{3}$ Although the separation of purchaser and provider responsibilities is to be retained, the four regional health authorities are to be replaced by a central funding body. In parallel the crown health enterprises, which manage services, will be superseded by regional hospital and community services agencies. One of the objectives of these changes is to limit bureaucracy and reduce transaction costs.

Governing through coalitions is new to New Zealand, and the statement on health policy reflects the inevitable compromises involved in such arrangements. It is also open to alternative interpretations, ranging from "business as usual" to a complete about 
face. What does seem clear is that big bang reform has given way to incrementalism. With the general direction of policy having been set, the government has announced that the planned changes will be introduced gradually over time in order to minimise disruption. This reflects concern at reorganisation fatigue among health service staff as well as the rethinking that has occurred among politicians.

Alongside incrementalism there is a heavy dose of pragmatism in the government's plans. Having turned its back on competition, the coalition has stressed the need to focus on achieving health outcomes and improving the health status of the population; strengthening children's services, mental health services, and health services for Maori; and developing an approach based on family health teams for delivering some primary care services. The importance of integrated care is being emphasised as both politicians and health professionals recognise the need for team working and coordination of delivery of services after a period in which competition has militated against such an approach. This includes the further development of networks of general practitioners that have taken responsibility for budgets for some services (p 1890), although any extension of this scheme will have to be approved by the health minister.

The experience of New Zealand is instructive for what it tells us about the path that lies ahead for other countries that have flirted with healthcare markets and are now having second thoughts. The United Kingdom, Sweden, and the Netherlands have all pursued changes similar to those initiated in New Zealand in 1993, and in each case the changes have been modified, often quite substantially. To this extent, the vogue for competition seems to have passed, and healthcare reform is entering a new phase. As this happens, not only is the content of the agenda for health policy changing but there are also signs of greater humility on the part of politicians about their ability to improve performance. The conviction that policy objectives can be better achieved by turning existing systems upside down has given way to a more sober appreciation of the limits of political action. Further changes are planned, but more in the spirit of tackling key problems and working with professionals and managers on possible solutions rather than imposing radical reforms across the board.

The key challenge in all of these systems is that of funding and rationing the health service. The work done in New Zealand by the National Health Committee may have disappointed some by failing to define the core services to be funded, but, through the programmes to develop guidelines for service provision and priority criteria for waiting lists, it has indicated an alternative approach. ${ }^{6}$ And by making a clear commitment to increase public spending on health care, the coalition government has recognised the concerns of healthcare professionals and the public about the pressures under which services are working. The impact of the National Health Committee's work remains uncertain and could yet rebound on politicians by increasing the pressure to allocate yet more resources to health care, but at least a start has been made in tackling the challenge of rationing.

The honesty with which these issues are debated, and the willingness of the health ministry to discuss the difficulties of priority setting openly, holds lessons for other countries. Not least, politicians must acknowledge that "rationing in any health system ... is inevitable" and face up to the consequences. This includes thinking about the role of private funding in support of public funding, given the difficulties of increasing public resources for health care in a climate of constraints on public spending and resistance to increased taxes. In the UK, the decision of the new Labour government to initiate a comprehensive review of public expenditure has started this process. In the next phase of healthcare reform the litmus test for politicians in all countries is their willingness to lead this debate and to share with the public the dilemmas of setting priorities as the gap between demand and supply widens.

\section{Chris Ham Director}

Health Services Management Centre, University of Birmingham B15 2RT

1 Hornblow A. New Zealand's health reforms; a clash of cultures. BMJ 1997;314:1892-4.

2 Crown Company Monitoring Advisory Unit. Crown Health Enterprises: briefing to the incoming minister. Wellington: Crown Company Monitoring Advisory Unit, 1996

3 Agreement between New Zealand First and the New Zealand National Party. Wellington, 1996.

4 Coney S. Business as usual for New Zealand's health care. Lancet 1997;349:37.

5 Malcolm L. GP budget holding in New Zealand: lessons for Britain and elsewhere? BMJ 1997;314:1890-2.

6 Hadorn D, Holmes AC. The New Zealand priority criteria project. Part l: Overview. BMJ 1997;314:131-4.

7 Ministry of Health. Healthy New Zealanders: briefing papers for the minister of health 1996. Vol 1. Key policy issues. Wellington: Ministry of Health, 1996: 25.

\title{
Vitamin $\mathrm{E}$ and cardiovascular protection in diabetes
}

\author{
Antioxidants may offer particular advantage in this high risk group
}

A theromatous vascular disease is responsible for $70 \%$ of deaths in patients with diabetes and a twofold to fourfold excess mortality in those with impaired glucose tolerance. ${ }^{1}$ Although diabetes is an independent risk factor for cardiovascular disease, some excess risk may also be related to the association of diabetes with other risk factors, including hyperlipidaemia and hypertension in the "metabolic syndrome."
However, treating these risk factors is unlikely to have a major impact on cardiovascular complications associated with diabetes. ${ }^{2}$ New approaches to reducing cardiovascular risk in diabetes need to be assessed.

Increased awareness of the role of oxidative stress in the pathogenesis of atheroma ${ }^{3}$ has opened new avenues for research. One peroxidation product, oxidised low density lipoprotein (ox-LDL), damages 
the vascular endothelium and is potently atherogenic. It impairs endothelium dependent relaxation, which is mediated by nitric oxide, an endogenous vasodilator with antiatherogenic properties. Impaired endothelium dependent relaxation may be a surrogate marker of later atherosclerosis, and may precede the formation of fatty streaks, the macroscopic precursors of more advanced atherosclerotic lesions. ${ }^{4}$

Endothelial dysfunction and increased concentrations of oxidised low density lipoprotein were initially demonstrated in subjects with hypertension and hypercholesterolaemia, and have now been shown in people with diabetes. ${ }^{5}$ Vitamin $\mathrm{E}$ is lipophilic and, when incorporated into the low density lipoprotein particle, inhibits its oxidation. Since vitamin E concentrations are reduced in some patients with diabetes and oxidative stress is enhanced, ${ }^{6}$ dietary supplementation with vitamin $\mathrm{E}$ is a logical approach to reducing the incidence of atheromatous vascular complications associated with diabetes.

Two recent studies have addressed the issue of vitamin E supplementation in the secondary prevention of coronary heart disease. In an uncontrolled trial Hodis et al showed that oral supplements of at least $100 \mathrm{IU}$ a day of vitamin $\mathrm{E}$ reduced progression of coronary atheroma in patients taking cholesterol lowering treatment. $^{7}$ Most recently, the Cambridge heart antioxidant study (CHAOS) showed a 77\% reduction in non-fatal myocardial infarction in patients with angiographically proved coronary heart disease who took 400 or $800 \mathrm{IU}$ of vitamin $\mathrm{E}$ daily. ${ }^{8}$ The study included few patients with diabetes, and it is not possible to ascertain whether this subgroup would have benefited more than non-diabetic patients from antioxidant treatment.

Several lines of evidence suggest the potential benefits of vitamin $\mathrm{E}$ in diabetes. Firstly, the low density lipoprotein of individuals with non-insulin or insulin dependent diabetes causes accumulation of cholesterol in cultured human intimal aortic cells. ${ }^{9}$ This low density lipoprotein is structurally different from that of healthy volunteers and contains a small, dense fraction that is easily oxidised. ${ }^{10}$ Whether this is due to non-enzymatic glycosylation of lipoproteins, lipid content, or other changes within or outside the low density lipoprotein particle is uncertain. What is certain is that oral supplementation with vitamin $\mathrm{E}$ delays the oxidation of all low density lipoprotein subfractions in response to oxidative stress. ${ }^{15}$

Secondly, recent work has shown that supplementation with oral vitamin $\mathrm{E}$ prevents abnormalities of endothelium dependent relaxation of the aorta and coronary arteries in rats rendered diabetic by streptozotocin. ${ }^{11}$ The mechanism of endothelial dysfunction associated with diabetes is incompletely understood but may involve decreased production or increased inactivation of endothelium derived nitric oxide. Oxidised low density lipoprotein down regulates production of nitric oxide ${ }^{12}$ and may also interact with nitric oxide to reduce its bioavailability. Vitamin E may thus enhance release of nitric oxide and inhibit its breakdown, leading to greater bioavailability and improved endothelial function.

Thirdly, insulin resistance and hypertension are potent risk factors for the development of cardiovascular disease. Chronic administration of vitamin $\mathrm{E}$ improves insulin sensitivity, ${ }^{13}$ and injection of vitamin
C, thiopronine, or glutathione-all antioxidants-will acutely reduce blood pressure in individuals with diabetes, ${ }^{14}$ possibly by increasing availability of endothelium derived nitric oxide. Furthermore, the new insulin sensitising drug, troglitazone, contains the vitamin $\mathrm{E}$ moiety and, in addition to improving insulin resistance, has been shown to lower blood pressure in normotensive, glucose intolerant subjects. ${ }^{15}$

The relation between endothelial dysfunction and atherogenesis remains unclear. Oxidised low density lipoprotein may be a common factor in the development of atheroma in hypertension, hypercholesterolaemia, and diabetes. Antioxidant treatment offers potential benefits, and the case for further examination of the relation between antioxidants and vascular disease in the general population has been made. Current evidence is insufficient to recommend intervention trials targeted at subjects with diabetes. However, they should be actively recruited into future studies examining the relation between atheroma, oxidative stress, and antioxidants, as vitamin E may offer particular advantage to this group at high risk of cardiovascular disease.

\section{Anastasios Gazis Clinical research fellow \\ Simon Page Consultant physician \\ John Cockcroft Senior lecturer}

Department of Medicine and Department of Diabetes, Endocrinology and Nutrition, University Hospital, Queen’s Medical Centre,

Nottingham NG7 2UH

1 Fuller JH, Shipley MJ, Rose G, Jarrett RJ, Keen H. Coronary-heart-disease risk and impaired glucose tolerance: the Whitehall study. Lancet 1980;i:1373-6.

2 Yudkin JS. How can we best prolong life? Benefits of coronary risk factor reduction in non-diabetic and diabetic subjects. BMJ 1993;306:1313-8.

3 Alexander RW. hypertension and the pathogenesis of atherosclerosis. Oxidative stress and the mediation of arterial inflammatory response: a new perspective. Hypertension 1995;25:155-61.

4 Ross R. The pathogenesis of atherosclerosis: a perspective for the 1990s. Nature 1993;362:801-9.

5 Poston L, Taylor PD. Endothelium-mediated vascular function in insulindependent diabetes mellitus. Clin Sci 1995;88:245-55.

6 Sundaram RK, Bhaskar A, Vijayalingam S, Viswanathan M, Mohan R, Shanmugasundaram KR. Antioxidant status and lipid peroxidation in type II diabetes mellitus with and without complications. Clin Sci type II diabetes

7 Hodis HN, Mack WJ, LaBree L, Cashin-Hemphill L, Sevanian A, Johnson $\mathrm{R}$, et al. Serial coronary angiographic evidence that antioxidant vitamin intake reduces progression of coronary artery atherosclerosis. JAMA 1995:973:1849-54.

8 Stephens NG, Parsons A, Schofield PM, Kelly F, Cheeseman K, Mitchinson MJ, et al. Randomised controlled trial of vitamin E in patients with coronary disease: Cambridge heart antioxidant study (CHAOS). Lancet 1996;347:781-6.

9 Sobenin IA, Tertov VV, Koschinsky T, Bünting CE, Slavina ES, Dedov II, et al. Modified low density lipoprotein from diabetic patients causes cholesterol accumulation in human intimal aortic cells. Atherosclerosis 1993;100:41-54.

10 Reaven P. Dietary and pharmacologic regimens to reduce lipid peroxidation in non-insulin-dependent diabetes mellitus. Am J Clin Nutr 1995;62:1483-9S.

11 Keegan A, Walbank H, Cotter MA, Cameron NE. Chronic vitamin E treatment prevents defective endothelium-dependent relaxation in diabetic rat aorta. Diabetologia 1995;38:1475-8.

12 Liao JK, Shin WS, Lee WY, Clark S. Oxidized low-density lipoprotein decreases the expression of endothelial nitric oxide synthase. Circulation 1994;90(4 part 2):I407.

13 Paolisso G, D'Amore A, Giugliano D, Ceriello A, Varricchio M, D’Onofrio F. Pharmacologic doses of vitamin $\mathrm{E}$ improve insulin action in healthy subjects and non-insulin-dependent diabetic patients. Am J Clin Nutr 1993;57:650-6.

14 Ceriello A, Giugliano D, Quatraro A, Lefebvre PJ. Anti-oxidants show an anti-hypertensive effect in diabetic and hypertensive subjects. Clin Sci 1991;81:739-42.

15 Nolan JJ, Ludvik B, Beerdsen P, Joyce M, Olefsky J. Improvement in glucose tolerance and insulin resistance in obese subjects treated with troglitazone. N Engl J Med 1994;331:1188-93. 


\title{
HIV associated tuberculosis
}

\author{
A barometer for wider tuberculosis control and prevention
}

$\mathrm{P}$ eople who are infected with HIV are at an increased risk of contracting tuberculosis. The WHO estimates that just over 20 million people are currently infected with HIV and of these 6 million are co-infected with Mycobacterium tuberculosis. Worldwide there has been a resurgence of tuberculosis, mainly in developing countries but also in the United States and Europe. Between 1987 and 1993 tuberculosis rates increased by $35.5 \%$ in London (with the increase most notable in inner London) compared with 15\% in England and Wales as a whole. ${ }^{12}$ However, it is unclear to what extent the prevalence of HIV associated tuberculosis has increased in the capital, largely because notification of tuberculosis in the HIV infected population is unreliable and probably underestimates the problem. ${ }^{3}$ Nosocomial spread has occurred in several specialist HIV centres in Britain and elsewhere, and drug (and multidrug) resistance is a growing problem. ${ }^{45}$ Because of the shortened incubation period for tuberculosis, HIV infection highlights weaknesses in tuberculosis control programmes.

Recent data from London have shown that HIV infected patients originating from Africa are at increased risk of developing tuberculosis, yet they are rarely offered preventive treatment. ${ }^{6}$ Furthermore, these patients may be unaware of their HIV status at presentation. ${ }^{67}$ Notification rates in black Africans have more than doubled recently, from $60.4 / 100000$ in 1988 to $135.2 / 100000$ in 1993. In contrast, rates have fallen in West Indians, people from the Indian subcontinent, and white people (J Watson, personal communication). With the high prevalence of HIV infection in parts of Africa and the global spread of HIV to other areas endemic for tuberculosis, tuberculosis clinics should be encouraged to increase testing for $\mathrm{HIV}^{8}$

In New York City the prevalence of tuberculosis is four times the American national rate, with nosocomial spread and multidrug resistant tuberculosis (that is, tuberculosis resistant to isoniazid and rifampicin with or without resistance to other antimicrobials) reaching a peak in the early 1990s. Enhanced infection control programmes in institutions (along with directly observed therapy) have contributed substantially to the more recent rate reductions. ${ }^{9}$ Microbial typing by restriction fragment length polymorphism can improve the detection of nosocomial spread and help detect clusters in the community. ${ }^{10}$ However, there is now greater possibility of litigation if procedures for infection control are not followed. Recent British recommendations encouraging a coordinated local approach are welcome but will need significant additional resources if they are to be adopted. ${ }^{11}$

Until recently, Britain has experienced only low levels of drug resistant tuberculosis. Between 1982 and 1991 only $0.6 \%$ of primary isolates were resistant to isoniazid and rifampicin. ${ }^{12}$ Provisional figures for 1994 in London, however, show 2.8\% of isolates from north Thames and $1.4 \%$ of isolates from south Thames region are multidrug resistant. ${ }^{13}$ Recent evidence suggests the risk of drug resistance and, in particular,

multidrug resistance is significantly greater in the HIV infected population, particularly among those who have been treated for tuberculosis before. ${ }^{4}$

Directly observed therapy for tuberculosis reduces the prevalence of acquired drug resistance, relapse, and, perhaps in the long term, primary drug resistance. ${ }^{5}$ In Britain, as in the United States, it is recommended for "non-compliant patients, and those likely to be non-compliant." ${ }^{14}$ However, compliance with antituberculous treatment is notoriously unpredictable. In Britain there is a national shortage of clinical nurse specialists in tuberculosis, and district nurses may be unwilling or unable to take on this service. As a result, directly observed therapy cannot be implemented effectively.

HIV associated tuberculosis is a barometer for tuberculosis control. Efforts should be concentrated on early identification of patients with infectious tuberculosis, early initiation of effective treatment, and effective screening of patients with tuberculosis for HIV and vice versa. Improved control of tuberculosis in this group and in the population as a whole will depend on improved facilities for isolating patients with infectious tuberculosis and wider use of directly observed therapy. Additional resources and funding are needed.

\section{Richard Coker Consultant physician}

Departments of Genitourinary Medicine, HIV, and Respiratory Medicine, St Mary's Hospital NHS Trust, London W2 1NY

\section{Rob Miller Senior lecturer}

Division of Pathology and Infectious Diseases, University College London Medical School, London WC1E 6AU

1 Office for Population Censuses and Surveys. Communicable disease 1987-90. London: HMSO, 1988, 1992. (Series MB2, Nos 14-17.)

2 Office of Population Censuses and Surveys. Weekly returns. London: HMSO, 1993.

3 Pym AS, Churchill DR, Gleissberg V, Coker RJ. Notification of tuberculosis in patients with HIV infection. BMJ 1995;311:570.

4 Bennett DF, Howitt D, Herbert J, Brady AR, Watson JM. TB, HIV and drug resistance in England and Wales, 1993-95 [abstract]. Tuber Lung Dis 1996;77(suppl 2):91.

5 Weiss SE, Slocum PC, Blais FX, King B, Nunn M, Matney GM, et al.The effect of directly observed therapy on the rates of drug resistance and relapse in tuberculosis. N Engl J Med 1994;330:1179-84.

6 Del Amo J, Petruckevitch A, Phillips AN, Johnson AM, Stephenson JM, Desmond N, et al. Spectrum of disease in Africans with AIDS in London. AIDS 1996;10:1563-9.

7 Poznansky M, Coker R, Skinner C, Hill A, Bailey S, Witaker L, et al. HIV positive patients first presenting with an AIDS defining illness: characteristics and survival. BMJ 1995;311:156-8.

8 Department of Health. HIV and AIDS health promotion: an evolving strategy. London: DoH, 1995.

9 Frieden TR, Fujiwara PI, Washko RM, Hamburg MA. Tuberculosis in New York City-turning the tide. N EngJ Med 1995;333:229-33.

10 Small PM, Hopewell PC, Singh SP, Paz A, Parsonnet J, Ruston DC, et al. The epidemiology of tuberculosis in San Francisco-a population-based study using conventional and molecular methods. N Engl I Med study using con
1994;330:1703-9.

11 The Interdepartmental Working Group on Tuberculosis. The prevention and control of tuberculosis in the United Kingdom: recommendations for the prevention and control of tuberculosis at local level. London: Department of Health, 1996.

12 The surveillance, prevention and control of tuberculosis in London: the report of the working party on tuberculosis of the London group of consultants in communicable disease control. London:United Medical and Dental Schools of Guy's and St Thomas's Hospitals, 1995.

13 Warburton ARE, Jenkins PA, Waight PA, Watson JM. Drug resistance in initial isolates of Mycobacterium tuberculosis in England and Wales, 1982-1991. Commun Dis Rep CDR Rev 1993;13:175-9.

14 Bradford WZ, Martin JN, Reingold AL, Schecter GF, Hopewell PC, Small PM. The changing epidemiology of acquired drug-resistant tuberculosis in San Francisco, USA. Lancet 1996;348:928-31. 


\title{
Devolution and the Scottish NHS
}

\author{
Scotland's needs may be better addressed after devolution
}

$\mathrm{S}$ cotland, with a population of five million people, is in that respect comparable to an English health region. Thereafter, similarities fade. Responsibilities for the NHS in Scotland lie, not with a regional authority, but directly with a Scottish Office minister and his civil servants in St Andrew's House, Edinburgh. Per capita spending on health is higher in Scotland than in England, yet many health indicators remain obstinately worse. And even the history of the NHS in Scotland is different; a separate piece of legislation-the National Health Service (Scotland) Act 1947-established different procedures for appointing consultants and greater participation by universities in the running of the service, and sought to ensure that "the special virtues of the Highlands and Islands Medical Service would be protected and extended to the nation as a whole."

More recent reforms, seen as driven by the problems and politics of England, have been generally less admired. Market led and quango based solutions, at odds with a social and political culture more left leaning and less deferential than that south of the border, were never convincing. The new British government's commitment to replace competition with collaboration, reduce the number of NHS trusts, and end general practitioner fundholding has therefore been generally welcomed in Scotland.

Yet that may prove to be just the beginning. A bill about to go before parliament will almost certainly lead to a referendum this autumn on devolution for Scotland. With Scottish public opinion running at around three to one in favour of a Scottish parliament and two to one in favour of that body having powers to vary levels of taxation, ${ }^{2}$ the likelihood is that substantial responsibilities for the Scottish health service will, within a few years, fall to ministers accountable to members of a Scottish parliament gathered in a former school assembly hall in Edinburgh.

Only slowly are the possibilities thus raised being recognised by health professionals and others in Scotland. In February a one day conference-"Health and a Scottish Parliament"-concluded that "The establishment of a Scottish parliament with broad and accountable responsibilities for health service provision in Scotland may offer a unique opportunity to look afresh at the healthcare needs of the people of Scotland and to refashion services to meet these needs." The conference recognised the multifactorial nature of much of Scotland's ill health and acknowledged the need for multi-agency solutions incorporating matters of housing, employment, transport, and education policy as well as simply those of health. The conference recommended a public health ministry with responsibilities for monitoring key local and national indicators of health and for transdepartmental coordination of health related policies.
As elsewhere in the United Kingdom, there are concerns about how to maintain access to the best of acute medical care when the efficient and safe delivery of that care dictates that it be concentrated at fewer and fewer sites. Competing trusts under the loose strategic tutelage of enfeebled health boards have conspicuously failed to address this issue. If a national strategy for tiered services-national, regional, and local-can be agreed Scotland, with good internal communications and the great majority of its population within two hours' travelling time of the two main centres, can do better as a nation than as an agglomeration of boards and trusts.

Scotland has several advantages on which postdevolution developments in health care might build. The problem of the quangocracy has already been addressed by the Scottish Office Health Appointments Advisory Committee, which pioneered a new and independent system of appointments to public bodies: transparent, based on merit, and commended by the Nolan committee (the government's committee on standards in public life) in its first report. There is not much in the way of private practice, little metropolitan dominance, and precious little regional alienation.

At a time of great political fluidity, doctors can and should lead a debate on Scotland's health care that welcomes also politicians, managers, other health professionals, and, above all, the Scottish public. In November a symposium sponsored by the three colleges will address the public health and organisational opportunities that devolution might raise for the NHS in Scotland. Rationalisation of acute services within a national strategy may be one obvious recommendation; and the colleges themselves might consider the formation of a national academy of medicine that still preserved individual identities and their valued links with London.

The prospects are perhaps as vivifying as those of 1948, but the ultimate test of any post-devolution settlement is a long term one: the improvement of the health of the people of Scotland. And if at some future date regional autonomy in England offers similar opportunities in Yorkshire, the midlands, the south west, etc, instruction may be available from our achievements-and from our mistakes.

Colin Currie Senior lecturer in geriatric medicine University of Edinburgh Medical School, EH8 9AG

Anthony Toft Consultant physician

Royal Infirmary of Edinburgh, EH3 9YW

\footnotetext{
1 Webster C. The health services since the war. Vol 1. London: HMSO, 1988:104.

1988:104.
ICM Poll. Scotsman 1997 Jun 18:1.

3 Health and a Scottish parliament: a report on a participatory conference. Edin-
} burgh: Hobsbawm Macaulay Communications, 1997. 